\title{
Diplopia as a Presenting Symptom of Diabetes Mellitus
}

\section{CASE REPORT}

Ünsal Aydoğan Y 1, Kaplan Efe F 1, Deveci S 1, Beyan E 1, Morkavuk G 2, Altay M 1

1 Keçiören Training and Research Hospital, Internal Medicine Clinic

2 Keçiören Training and Research Hospital,,Neurology Department persisting for 15 days. Cranial images revealed no abnormal findings. Patient was directed to internal medicine clinic due to the complaints of weight loss, thirst and polyuria in detailed interrogation. Due to detecting fasting blood glucose level of $317 \mathrm{mg} / \mathrm{dL}$ and postprandial blood glucose level of $535 \mathrm{mg} / \mathrm{dL}$ in laboratory tests, he was admitted to the internal medicine service. HbAlc was measured as $12 \%$. Insulin therapy was initiated. When the patient was consulted to clinic of ophthalmology, the 6 th cranial nerve palsy was identified and recommended a clinic of ophthalmology control every six months. He was discharged with advice to go to the clinic control. advanced age and long standing, poorly controlled DM. It should be kept in mind that DM can be diagnosed with non-specific and rare symptoms of eyes such as diplopia. 